\title{
Neoindustrial paradigm of Russia based on fourth industrial revolution technologies and human capital development
}

\author{
Maksutina Elena Vladimirovna \\ $\mathrm{NChI}$ Department of economic theory and economic policy \\ Kazan Federal University, \\ Kazan, Russia \\ lena.betty@mail.ru \\ Sokolova Inessa Albertovna \\ NChI Department of Foreign Languages \\ Kazan Federal University, \\ Kazan, Russia \\ IASokolova@kpfu.ru
}

\author{
Makarov Anatolij Nikolaevich \\ NChI Department of economic theory and economic policy \\ Kazan Federal University, \\ Kazan, Russia \\ makarovfksu@yandex.ru
}

\author{
Golovkin Alexey Vyacheslavovich \\ Department of Metallurgical Production of PJSC \\ "AVTOVAZ" \\ Tolyatti, Russia \\ bear2003@inbox.ru
}

\author{
Galiakberova Alfinur Azatovna \\ NChI Department of economic theory and economic policy \\ Kazan Federal University, \\ Kazan, Russia \\ Alfinur.gali@yandex.ru
}

\begin{abstract}
The article is devoted to the issues of neoindustrialization of Russian economy on the basis of the implementation of the fourth industrial revolution model and the development of human capital. The urgency of the theme lies in the need to form a new model for the growth of Russian economy, based on the revival of industrial production in conditions of a global transformation of the world system of labor division under the influence of innovative technologies of the fourth industrial revolution large-scale introduction. The conceptual foundations of the new industrialization are studied, the influence of the industrial revolution on the labor market and population employment, development of industries forming human capital are shown. The aim of new industrialization is the technological re-equipment of production on the basis of the latest technological developments as the most important condition for the successful development of the economy and ensuring the economic and technological security of the country. The main technological directions of neoindustrialization that may lead to the expected revolutionary changes are industrial Internet, 3D-printing or additive production, production robotization, bionic design. The paper analyzes the possibility of innovative explosive growth and expansion of the range of the development of additive technologies at large industrial enterprises in Russia. The article focuses on specific steps for Russian economy neoindustrialization undertaken within the framework of the implementation of "National Technology Initiative" program projects.
\end{abstract}

Keywords -neoindustrial paradigm, the fourth industrial revolution, human capital, additive industrial technologies, national technology initiative, labor market.

\section{INTRODUCTION}

One of the main themes of the World Economic Forum in Davos has been the Fourth industrial revolution for many years, characterized, according to the chairman of the WEF, Klaus Schwab, by a combination of technologies that blur the boundaries between the physical, digital and biological spheres. Modern technologies change faster than ever, creating new challenges and identifying promising opportunities for development. Russia's response to the challenges of the fourth industrial revolution should be the new industrialization of the economy, based on the use of modern industrial technologies and the development of human capital

The best way to overcome the crisis phenomena and the prolonged depression caused by the Kondratiev cycles change, as the outstanding German economist Gerhard Menshhashas shown, is an innovation-technological breakthrough by timely mastering and distribution of the basic technologies of the sixth system of the Kondratiev cycle. Russia has a good chance to make this innovation-technological breakthrough on the upward wave of the forthcoming sixth cycle of Kondratiey (2018-2042) [1, p.34]. In order to solve this problem, the country has high scientific and technical potential and huge 
human resources, which should bring the innovative mechanism into action.

The issues of the influence of modern industrial technologies on labor market future and the world economy development, the determination of the place and the role of countries in the global change of the technological order, and the search for new sources of economic growth are among the priority areas of research in domestic and world science, they are discussed at prestigious scientific platforms and forums, such as the Gaydar Economic Forum in Moscow, the World Economic Forum in Davos, the St. Petersburg International Economic Forum [2, 3, 4].

The purpose of this work is to study the conceptual foundations of the neoindustrialization of the Russian economy, based on the implementation of the model of the fourth industrial revolution. It is also planned to assess the impact of the industrial revolution on the labor market and population employment, the industries that form human capital development, and to offer specific recommendations on expanding the use of industrial technologies in Industry 4.0 at Russian enterprises.

\section{RESULTS AND DISCUSSION}

Large-scale and colossal technological shifts are called technological or industrial revolutions. The first industrial revolution ensured the transition from manual labor to machine one. It is customary to associate it with the invention of a steam engine in the 17th century, but the process of transition from manufactories to a factory continued in different countries during the 18th and 19th centuries. The second industrial revolution was connected with the electrification and organization of conveyor production in the twentieth century, at first cars, and then most other products. At the beginning of the XXI century more and more publications on the theme of the third industrial revolution began to appear. It was based on the rejection of the use of minerals, the transition to renewable energy sources in combination with the introduction of computers into production, automation and the transition to digital production.

The great contribution to the theme of the third industrial revolution was made by the American economist Jeremy Rifkin. In his book "The Third Industrial Revolution: How Horizontal Interactions Change Energy, Economy and the World as a Whole," he paid special attention to "the green" energy. J. Rifkin outlined five principles on which the third industrial revolution is based: 1)the transition to renewable energy sources; 2) the conversion of all buildings into minipower stations; 3) the use of hydrogen energy; 4) the use of Internet technologies; 5) the production of electric vehicles [5]. Also J. Rifkin pays much attention to horizontal ties, the era of cooperation and property issues in new life conditions. The following year, after the publication of the book by J. Rifkin, the topic he raised was continued in the book by Peter Marsh "The New Industrial Revolution: Consumers, Globalization and the End of Mass Production" [6]. Peter Marsh analyzes the key changes that take place in industrial production today, including the emergence of new technologies, non-standard products aimed at an atypical buyer and the participation of a much larger number of countries in world production.
Despite the fact that the realities of the third revolution are far from spreading around the world, it turns into the fourth industrial revolution. The latter, according to the chairman of the World Economic Forum in Davos, Klaus Schwab, is characterized by technological breakthroughs in such areas as artificial intelligence, robotics, Internet of things, selfcontrolled automobiles, 3D printing, nanotechnology, biotechnology, materials science, energy storage and quantum computing [7].

The German program Industry-4 is connected with the concept of the fourth industrial revolution,, in which large German companies, with of the Federal Government support, create fully automated industries, where lines and products, interact with each other and with the consumers within the concept of the Internet of things. The key driving force of Industry 4.0 is the enhanced integration of "cyber-physical systems", or CPS, into production processes. This is the production part of the Internet of things that quickly penetrates into our lives.

New industrial revolution changes production, business, society and state. It also has a significant impact on labor market. The "Future of Jobs" report was prepared for the Davos World Economic Forum. It is makes society more than anxious. The development of new technologies in the next five years can lead to a reduction of 7 million jobs, which will be compensated by only 2 million vacancies in new areas of the economy. The problem is that the fourth industrial revolution creates a vector not to create new jobs, but to reduce them. The new industrial revolution will enable devices to interact without human intervention. It can lead to the inequality growth and the middle class erosion.

With the growth of labor productivity, inefficient employment will inevitably decline, which means that it is necessary to significantly increase the flexibility of labor market, to offer people new employment opportunities [8]. It is possible to solve this problem, first of all, creating new jobs in small and medium business, including in the high-tech sphere of the economy. One more niche for small and medium businesses is service, the development of household services sphere, and in fact, the creation of a comfortable, favorable environment for people's lives. In our opinion, no less capacious niche is agriculture, which also becomes an industrial one nowadays.

The National Technological Initiative is called to respond to the challenges of the technological revolution in Russia and represents a program of measures to create fundamentally new markets and create conditions for Russia's global technological leadership by 2035 . The program covers several branches: unmanned vehicles, aircraft and maritime transport; personalized medicine; artificial components of consciousness and psyche; personal security systems; decentralized financial systems and currencies; personal production systems and food and water delivery; distributed power.

In the AutoNet segment, the unconditional leader is the unmanned truck creation project, implemented by PJSC KAMAZ together with the developer of IT solutions Cognitive Technologies. Unmanned automobile systems are developed by many foreign companies, such as Google, Toyota, Ford, 
General Motors, Volkswagen, Volvo. A worthy competition to foreign projects in this area can be made by Russian developers now.

From our point of view, the development of unmanned vehicles will lead to the global economy changes. Countries with a large fleet of fleet of automotive equipment are under serious threat. This threat is associated with great risks for companies operating in the insurance business. Essential risks will also be experienced by the truckers servicing infrastructure. It is a car service, roadside cafes, motels, camping sites, gas stations, roadside shops, etc.

It is clear that unmanned vehicles will be less crash, as compliance with traffic rules and speed limits will be an indispensable condition for the car to move. A decrease of crash rate will also allow automakers to significantly change the design of cars. Passive safety systems will disappear or be upgraded, materials from which details will be manufactured will change. In general, the car is waiting for serious design and design solutions related to the change in the new movement paradigm.

From our point of view, another important project that will be implemented by the National Technological Initiative towards MariNet, is the all-Russian project "Pioneer M". It has both technical and educational significance. This is the first project where students and teachers will jointly design and then operate a ship that is built to the most modern standards of innovative shipbuilding. The vessel will have a module of unmanned or unmanned driving, as the sailors say.

No less important technology is also bionic design. It opens the world to new opportunities in designing, greatly facilitating the weight of structures and products. Bionic design is the optimization of constructions as a result of the convergence and synergy of two global trends - computer engineering, including optimization technologies, and 3D printings.

Modern industrial technologies are widely spread in the world, and Russia should not lag behind in this area. Neoindustrialization should become a paradigm for Russian economy development. At the same time, special attention should be paid to the development of industries that form the basis of the so-called fourth industrial revolution.

The conceptual foundations of neoindustrialization as a science-intensive, digital, and technotronic industrialization were substantiated by S.S. Gubanov in his book "Power Breakthrough. New industrialization of Russia and vertical integration" and consistently developed in the works of such scientists as S.Yu. Glazyeva, S.A. Tolkacheva, S.D. Bodrunov and other authors [9-11].

A great contribution to the interpretation and understanding of neoindustrialization essence was made by Professor S.S. Gubanov. In his book he gives the following definition to this concept: "New industrialization is understood as a historically natural process of productive forces development, which unfolds after the completion of the first phase of industrialization - electrification. It is the second phase of industrialization, i.e. automation and computerization of the production apparatus" [12]. The author distinguishes such important characteristics of the new industrialization as large- scale electronization and automation of production processes, the formation of intellectual labor as the dominant one, the further replacement of workers by machines. At the same time, some components of neo-industrial development require clarification and a more detailed correlation with the practical aspects of the unfolding under the influence of large-scale technologies introduction of the fourth industrial revolution of the new industrialization.

The concept of the new industrialization reflects the essence of those processes to which modern advanced societies have proceed. And today it can be argued that the paradigm of the postindustrial society with the primary development of the service sector is replaced by the economy model, the priority of which is industrial development on a new technological basis.

In our opinion, more accurately, the essence of the current wave of neoindustrialization is reflected in the interpretation of Professor S.A. Tolkacheva: "Neoindustrialization is a largescale introduction of a complex of breakthrough technologies into the production process, a fundamental change in the essence of the industrial production mode, the result of which will be the following:

- a sharp increase in labor productivity in manufacturing industries;

- the creation of new markets and the disappearance of some traditional activities;

- formation of global centers of fast industrial growth;

- radical reorganization of the existing system of the world division of labor by reducing the obsolete elements of the technological chain of previous orders, mainly in developing countries;

- reducing the need for unskilled labor and aggravating the global problem of unemployment;

- deepening of the technological superiority of industrialized countries over the rest of the world" [13, p.229].

Non-industrialization should become a paradigm for the Russian economy development, and the main goal of economic policy should be the industrial production revival on the basis of a large-scale introduction of the fourth industrial revolution technologies - by solving a set of interrelated economic, organizational and other tasks.

Industrialized countries are on the verge of a new industrial revolution, which has not yet received a generally accepted name. The terms "the fourth industrial revolution", "industry 4.0", "the sixth technological order", and others are used. Neoindustrialization in the search for a new model of economic growth is extremely important for Russia.

The new production paradigm is 3D-printing or additive production. Even with today's development of additive technologies, you can increase labor productivity in 20-30 times. The concentration of people in the enterprise will not be needed. The structure of enterprises will change. From the vertical it will turn into a structure that combines both vertical and horizontal connections. 
Thanks to the growing introduction of 3D-printing, in Russia there may appear a large number of individual entrepreneurs who will work at home in garages or small workshops. They will be able to create products that previously were within the power of only large enterprises. This creates excellent conditions for the development of individual entrepreneurship and small business, self-employment of population.

In order to implement these ideas, it is necessary to adopt a national program on neoindualization and self-employment of the population, based on the additive technologies development. The state allocates funds, and creates control mechanisms, determines the structure of the managing center, in which the mathematical models of various products will be stored. The Managing Center creates a site for the formation of orders, training video seminars, patent studies, all the necessary information for the production, as well as an online store of finished products. Orders should be of two categories. These are state orders and a stock exchange for individuals. The prototype is the freelance exchange. The applicant visits the site, gets acquainted with the work, the terms of implementation, the cost of work, technological moments, with the quality issues presented to this product, and concludes the contract. After doing the work, he sends it to the customer. By the way, something similar has already been created in the United States. In Chicago, Digital Lab launched an open online software platform for designing and collaborating in real time. But our Managing Center should have significantly more functions.

3D technologies have a wide development potential from the point of view of using crowdsourcing: a wide group of people will be involved into the production process using $3 \mathrm{D}$ printers, product design in accordance with differentiated consumer needs in different regions of the country and the world.

Enterprises that will attract a wide range of individual entrepreneurs for the production of products on the principles of crowdsourcing by the type of subcontract work using infocommunication technologies will be created. Entrepreneurs will have the opportunity to use ready-made mathematical models (in the online store) or develop them and exchange their three-dimensional models. This will contribute to the entrepreneurship development and population selfemployment.

The additive technologies are actively developing in the world. In Russia, this industry is not developing intensively.

Wide application of additive technologies at large enterprises in the country will allow one to intensify their development in Russia. We propose an approximate structure for the widespread use of additive technologies in production on the example of PJSC "AVTOVAZ":

the department of the additive production development is created;

the development laboratories on the basis of the Laboratory for Research department are organized; bureau for the introduction of additive technologies are created in production;

experimental development laboratories for all questions of interest of AVTOVAZ on the basis of the techno park are created;

the interaction with other additive technologies laboratories is realised in our country and abroad.

In manufacturing in the design and repair departments, 3D printers should be in every bureau. In order to increase the motivation of employees to use additive technologies, it is necessary to introduce the system of material incentives, just as it is done on rationalization proposals and with the same legal framework. A small reward is paid for each new application of parts made on 3D printers. Technological parks and innovative cities should become an experimental ground for additive technologies. Products similar to the head campaign, but by additive technology should be produced there.

All that is said cannot function without the participation of man and the development of the human capital [14]. Human capital is the driver of a new industrialization. And we need to start right from the kindergarten, giving the basics of modeling in a game form, developing and consolidating the knowledge gained in primary and secondary schools. The final formation of the chosen profession connected with additive technologies takes place in the higher educational institution. The choice is wide enough. These are such areas as medicine, biology, architecture, design, industrial production and much more. The ideal place for the technical development of children are children technoparks and innovative cities, such as Innopolis, located in the Republic of Tatarstan. Technical culture and a creative environment are formed there, preparing a child for new technical challenges. The example is the network of children technoparks "Kvantorium", created in the Russian regions [15].

Higher education institutions study complex design programs depending on the chosen specialty. In order to develop technology, it is necessary to train qualified staff. We suggest to actively create the chairs of additive technologies and bionic design in higher educational institutions based on the interface of biology and mechanics to develop additive "green technologies". Also, special attention should be paid to the staff training in the field of engineering and industrial design.

\section{CONCLUSION}

The urgency of the neoindustrialization issues is conditioned by the need to form a new model for the growth of Russian economy based on the revival of industrial production in the conditions of a global transformation of the world labor division system under the influence of large-scale introduction of the fourth industrial revolution technologies. The aim of new industrialization is the technological manufacturing reequipment on the basis of the latest technological developments - and in its turn is the most important condition for the successful development of Russian economy and ensuring economical and technological security of the country.

The most important technological directions of neoindustrialization that may lead to the expected revolutionary 
changes, corresponding to the fourth industrial revolution model, are: 3D printing or additive production, industrial Internet, production robotization, bionic design.

New industrial revolution will lead to the increase in the human capital role in the production process. Industry 4.0 can be called as the concept of "intellectual production", thus production through the human intellect.

Modern industrial technologies are widely distributed in the world, and Russia should not lag behind in this area. Russia has enough potential to count on medium term creation of conditions for its consolidation among the leading countries in the world economy on the basis of a new industrialization of the economy, increasing its global competitiveness and ensuring import of goods.

\section{References}

[1] V.A. Sadovnichy, A.A. Akaeva, A.V. Korotaeva, G.G. Malinetskiy, The Scenario and the perspective of the development of Russia. Moscow: LENARD, 2016, 320 p.

[2] B.Kuznetsov, V. E. Gimpelson, A. A. Yakovlev Industrialization in the Russian Federation, in: Structural Change and Industrial Development in the BRICS. NY: Oxford University Press, 2015. Ch. 6. pp. 138-161.

[3] M.R. Safiullin, I.G. Samigullin and L.N. Safiulli, "Model of Management of Competitiveness of a Machine-building Complex". World Applied Sciences Journal, vol. 27 (13), pp.212-216, 2013.

[4] L.I. Askhatova, A.M. Fatkhiev, L. N. Safiullin and A.M. Safiullina, "Competitive Strategies Formation in High Technology Enterprise". World Applied Sciences Journal, vol. 27 (13), pp. 20-23, 2013.

[5] J. Rifkin, The Third Industrial Revolution: How Horizontal Interactions Change Energy, Economy, World as a Whole, Moscow: Alpina nonfiction, 2014, $410 \mathrm{p}$.

[6] P. Marsh, New Industrial Revolution. Consumers, globalization and the end of mass production / trans. with English. Anne Sholomitskaya, Moscow: Publishing House of Gaidar Institute, 2015, 420 p.

[7] Klaus Swab, The Fourth Industrial Revolution: the translation from English, Moscow: Publishing House "E", 2017, 208 p.

[8] E.S. Alpatova, A.N. Makarov, E.V. Maksutina, E.F. Nazmeev, "Modern labor market in Russia and its regulation", Life Science Journal. Vol. 11. No. 6s. pp. 350-353, 2014.

[9] S. Yu. Glazyev, The strategy of advanced development of Russia in the conditions of the global crisis: monograph, Moscow: Economics, 2010, $255 \mathrm{p}$.

[10] S.A. Tolkachev, K.N. Andrianov, N.V. Lapenkova "Intellectual production through the prism of the third industrial revolution". The world of a new economy. vol. 6. pp. 28-38, 2014.

[11] S.D. Bodrunov, Formation of the strategy of reindustrialization of Russia: monograph, In two parts. Part one, SPB.: INIR, 2015, 551 p.

[12] S.S. Gubanov Power breakthrough. Neoindustrialization of Russia and vertical integration, Moscow: Book World, 2012, 224 p.

[13] K.N. Andrianov, S.A. Tolkachev, Industrial Policy in New Industrialization conditions: Monograph, Moscow: MAX Press, 2015, $252 \mathrm{p}$.

[14] E.V. Maksutina, A.N. Makarov, E.F. Nazmeev, E.S. Alpatova "Assessment of the economic efficiency of investments into the human capital in modern conditions" Life Science Journal. Vol. 11. No. 6s. pp. 376-379, 2014.

[15] I.S. Glebova, R. Sadyrtdinov, D. Rodnyansky, "Impact Analysis of Investment Attractiveness of the Republic of Tatarstan on Fixed Investments of its Leading Companies". World Applied Sciences Journal, vol. 26 (7), pp. 911-916, 2013 